\title{
Factors Associated with Compliance to the Hospital Price Transparency Final Rule: a National Landscape Study
}

\author{
John Xuefeng Jiang, PhD', Daniel Polsky, PhD'2,3, Jeff Littlejohn, MS ${ }^{4}$, Yuchen Wang, $B S^{3}$, \\ Hossein Zare, PhD', and Ge Bai, PhD, CPA 2,3
}

${ }^{1}$ Michigan State University Broad College of Business, East Lansing, MI, USA; ${ }^{2}$ Department of Health Policy and Management, Johns Hopkins Bloomberg School of Public Health, Baltimore, MD, USA; ${ }^{3}$ Johns Hopkins Carey Business School, Baltimore, MD, USA; ${ }^{4}$ Turquoise Health Co., San Diego, CA, USA 2021

BACKGROUND: The Hospital Price Transparency Final Rule, effective January 1, 2021, requires hospitals to post online a machine-readable file that includes payer-specific negotiated commercial prices for all services. The regulation aims to improve the affordability of hospital care by promoting price competition. However, a low compliance level among hospitals would compromise the operational effectiveness of this regulation. Understanding hospitals' compliance status to the regulation has important implications for its enforcement effort and effectiveness assessment.

OBJECTIVE: To analyze nationwide hospitals' compliance status to the Hospital Price Transparency Rule.

DESIGN: Cross-sectional observational study.

PARTICIPANTS: A total of 3558 Medicare-certified general acute-care hospitals were examined.

MAIN MEASURES: A binary compliance rating was generated by using data collected by Turquoise Health. "Noncompliance" means that no machine-readable file was posted or the posted file contains no commercial negotiated prices. "Compliance" means that a machinereadable file was posted with commercial negotiated prices for at least one insurance plan.

KEY RESULTS: As of June 1, 2021, 55\% of the 3558 Medicare-certified general acute-care hospitals we examined had not posted a machine-readable file containing commercial negotiated prices. Wide variations of compliance existed across states and hospital referral regions. A hospital's compliance status is strongly associated with the average compliance status of peer hospitals in the same market. Hospitals with greater IT preparedness, for-profit hospitals, system-affiliated hospitals, large hospitals, and non-urban hospitals had greater compliance. More concentrated hospital markets had greater average compliance.

CONCLUSIONS: Hospitals take into consideration the behavior of their peers in the same market when making price disclosure decisions. Compliant hospitals are likely to have better IT preparedness, more financial resources and personnel expertise to mitigate the cost required for the implementation of the Price Transparency Rule. The compliance cost, therefore, might be a barrier for some hospitals.
$\mathrm{J}$ Gen Intern Med 37(14):3577-84 DOI: $10.1007 / \mathrm{s} 11606-021-07237-\mathrm{y}$

(c) Society of General Internal Medicine 2021

\section{INTRODUCTION}

The Hospital Price Transparency Final Rule, effective January 1, 2021, aims to improve the affordability of hospital care by promoting price competition. ${ }^{1}$ The Rule requires that hospitals in the USA post a machine-readable file listing the payer-specific negotiated prices, discounted cash prices, and standard charges for all services. Hospitals also should have a consumer-friendly display of the same price information for 300 shoppable services. ${ }^{2}$ Noncompliant hospitals can face a daily civil monetary penalty of up to $\$ 300 .^{2}$ On July 19, 2021, the Centers for Medicare and Medicaid Services proposed to increase the daily penalty to $\$ 10$ per bed, up to $\$ 5500$ for hospitals with more than 30 beds. ${ }^{3}$ Hospitals and their trade associations have opposed this regulation by challenging it in court and petitioning for the delay of its implementation, reportedly because of compliance burdens and concerns that disclosing payer-specific negotiated prices violated contract confidentiality. ${ }^{4,5,6}$

Understanding hospitals' compliance status to the new Price Transparency Rule has important implications for its enforcement effort and effectiveness assessment. Using data obtained in January and February 2021, a study found that $82 \%$ of the 100 largest hospitals did not disclose commercial negotiated prices. ${ }^{7}$ Based on data obtained in March 2021, a study found that half of the 71 National Cancer Institute-designated cancer centers did not disclose commercial negotiated prices. ${ }^{8}$ Another study using data obtained in March 2021 found that $67 \%$ of 100 randomly selected hospitals and $65 \%$ of the largest 100 hospitals did not disclose commercial negotiated prices. ${ }^{9}$ To date, empirical evidence on compliance status based on large samples of hospitals remains unavailable. In this study, we analyzed the nationwide hospitals' compliance status to the Hospital Price Transparency Rule, using data obtained on June 1, 2021. 


\section{METHODS}

\section{Data and Sample}

Hospitals' compliance status was provided by Turquoise Health, a leading data service company that specializes in collecting hospitals' price information. ${ }^{10}$ Its compliance and pricing information has been used in several recent studies. ${ }^{1-13}$ As of June 1, 2021, Turquoise Health had reviewed all 4449 general acute-care hospitals included in the 2019 Medicare Cost Report. ${ }^{14}$ Among them, 891 hospitals' machine-readable files cannot be automatically processed because their data storage formats require manual processing. ${ }^{15}$ After they were excluded, the final sample contained 3558 hospitals, whose discharges accounted for $88 \%$ of all discharges of the 4449 hospitals in 2019. All financial and operational information of these hospitals was obtained from the 2019 Medicare Cost Reports. ${ }^{14}$

\section{Measurement}

The Hospital Price Transparency Rule requires that hospitals post a machine-readable file for all services and a consumer-friendly display (a list or a weblink) for 300 shoppable services. In this study, we focused on the machine-readable file because no insurance information is needed to access this file. We generated a binary compliance rating. "Noncompliance" means that no machinereadable file was posted or the posted file contains no commercial negotiated prices. "Compliance" means that a machine-readable file was posted with commercial negotiated prices for at least one insurance plan. This classification was simple and straightforward. It limited the subjectivity in measurement but is unable to capture the differences among hospitals' compliance (e.g., the number of shoppable services disclosed, and whether discounted cash prices and standard charges were missing).

To understand factors potentially associated with hospital price transparency, we examined each hospital's bargaining power by calculating its system-adjusted market share (the share of discharges from that hospital and its system-affiliated hospitals in the same hospital referral region (HRR)). ${ }^{16,17}$ Specifically, we obtained each hospital's all-patient discharges from the 2019 Medicare Cost Reports (Worksheet S-3 Part I Column 15 Line 14) and calculated the total discharges across hospitals for each HRR. Next, we identified hospitals in the same HRR affiliated with the same health system (system name reported on Worksheet S-2 Part I Column 1 Line 141) and calculated their combined discharges in the HRR. For these hospitals, their system-adjusted market share is their combined discharges in the HRR divided by the total discharges in the HRR. If a hospital does not share an affiliated health system with any other hospital in the same
HHR, its system-adjusted market share is its stand-alone market share, i.e., its own discharges divided by the total discharges in the HRR.

In addition, we examined each hospital's IT preparedness to bear the compliance burden by dividing the health IT assets, which is one type of fixed assets, by the total fixed assets. Specifically, we obtained the health IT assets amount for each hospital from the 2019 Medicare Cost Reports (Worksheet A-7 Column 6 Line 7). We then divided the health IT assets amount by the total fixed assets amount (Worksheet G Column 1 Line 30).

Moreover, we examined the following hospital characteristics suggested by prior literature to influence hospital behavior: ownership type (Worksheet S-2 Part I Column 1 Line 21), system affiliation (Worksheet S-2 Part I Column 1 Line 141), teaching status (Worksheet S-2 Part 1 Column 1 Line 56), urban/non-urban location (Worksheet S-2 Part 1 Column 1 Line 27), size (number of discharges), profit margin (overall net income divided by net patient revenue (Worksheet G-3 Column 1 Line 5 divided by Line 3)), charge markup (gross charge divided by Medicare-allowable cost (Worksheet C Part I Column 8 Line 202 divided by Column 5 Line 202)), and percentage of Medicare and Medicaid patient discharges (Worksheet S-3 Part I Column 13 Line 14 divided by Column 15 Line 14 and Worksheet S-3 Part I Column 14 Line 14 divided by Column 15 Line 14, respectively). ${ }^{16,18,19}$

Finally, we considered whether hospitals' price transparency choice is affected by peer hospitals by constructing a peer compliance for each hospital, measured as the average compliance rating of other hospitals in the same HRR. Because hospitals' compliance status is measured as a binary variable ( 1 if compliant; 0 if noncompliant), for any hospital the average compliance rating of other hospitals in the HRR where it is located takes the value between 0 and 1 .

\section{Statistical Analysis}

We examined the overall compliance rating of all 3558 hospitals in the sample and created a map using the average compliance rating of hospitals in each HRR. We identified HRRs in which all hospitals were compliant or no hospital was compliant, respectively, and ranked states based on the average compliance rating of their hospitals. Using a linear probability model, we conducted hospital-level multivariate regression analysis to estimate the effect of various factors on hospitals' compliance rating. We presented four model specifications-with or without state fixed effects (control for state-level heterogeneity), HRR fixed effects (control for HRR-level heterogeneity), and the peer compliance-to understand these factors' incremental predictive power in the model. For sensitivity analysis, we estimated a probit model using the same set of variables. 
We conducted HRR-level multivariate regression analysis to understand the variation in the average compliance rating across HRRs. For each HRR, we calculated the average values of the aforementioned variables, the number of hospitals in the market, the size of the market (total discharges), and market competitiveness (the discharge-based HerfindahlHirschman Index (HHI) adjusted for system affiliation). ${ }^{16}$ We analyzed the data and created figures using SAS 9.3 and STATA 16.

\section{RESULTS}

As of June 1, 2021, 55\% of the 3558 short-term acute-care hospitals we examined either did not post any machinereadable file or the file posted contained no commercial negotiated price information (compliance rating $=0$ ); the remaining $45 \%$ of hospitals posted commercial negotiated prices for at least one insurance plan for one or more services (compliance rating $=1$ ). In 64\% (194) of the 305 HRRs, more than half of the hospitals remained noncompliant. The average compliance rating among hospitals varied substantially across HRRs (Fig. 1 and Appendix Table 6). All hospitals in 20 HRRs (from 12 states) were compliant, and all hospitals in 26 HRRs (from 14 states) were noncompliant (Table 1). The average HHI across the HRRs was significantly higher in the 20 all-compliant HRRs than in the 26 all-noncompliant HRRs $(P=0.04)$. In the District of Columbia, Hawaii, Rhode Island, Indiana, and Michigan, at least $75 \%$ of hospitals were compliant, while in Delaware, Maryland, Washington, and Louisiana, at most $25 \%$ of hospitals were compliant (Table 2).

Hospital-level summary statistics are presented in Table 3, and the regression results are shown in Table 4. Consistent with the univariate evidence in Figure 1, hospitals' compliance rating varied widely across states and HRRs. Adding state fixed effects more than doubled the adjusted $R$-squares from the base model (4.8 to $12.6 \%$ ). Adding HRR fixed effects quadrupled the base model's adjusted $R$-squares (4.8 to $19.5 \%$ ). These estimated results suggest that state and HRR characteristics are associated with hospitals' compliance status. Even after controlling for the state fixed effects, the positive effect of the peer score-the average transparency score of all other hospitals in the same HRR — remained highly significant $(0.42$; $P<0.001)$. Based on this estimated coefficient, if all other hospitals in the same HRR switched from noncompliance to compliance, a hospital would be $42 \%$ more likely to become compliant as well. These results remained qualitatively unchanged when the 891 hospitals excluded from the sample (because their machine-readable files cannot be automatically processed) were reclassified as noncompliant and included in the sample.

Across all model specifications, a hospital's IT preparedness ( $P: 0.013-0.045)$, size $(P: 0.001-0.064)$, system affiliation $(P<0.001)$, system-adjusted market share within the HRR ( $P$ : 0.000-0.087), for-profit ownership (as compared to nonprofit) ( $P: 0.001-0.004)$, and non-urban location $(P: 0.000-0.006)$ were estimated to be positively

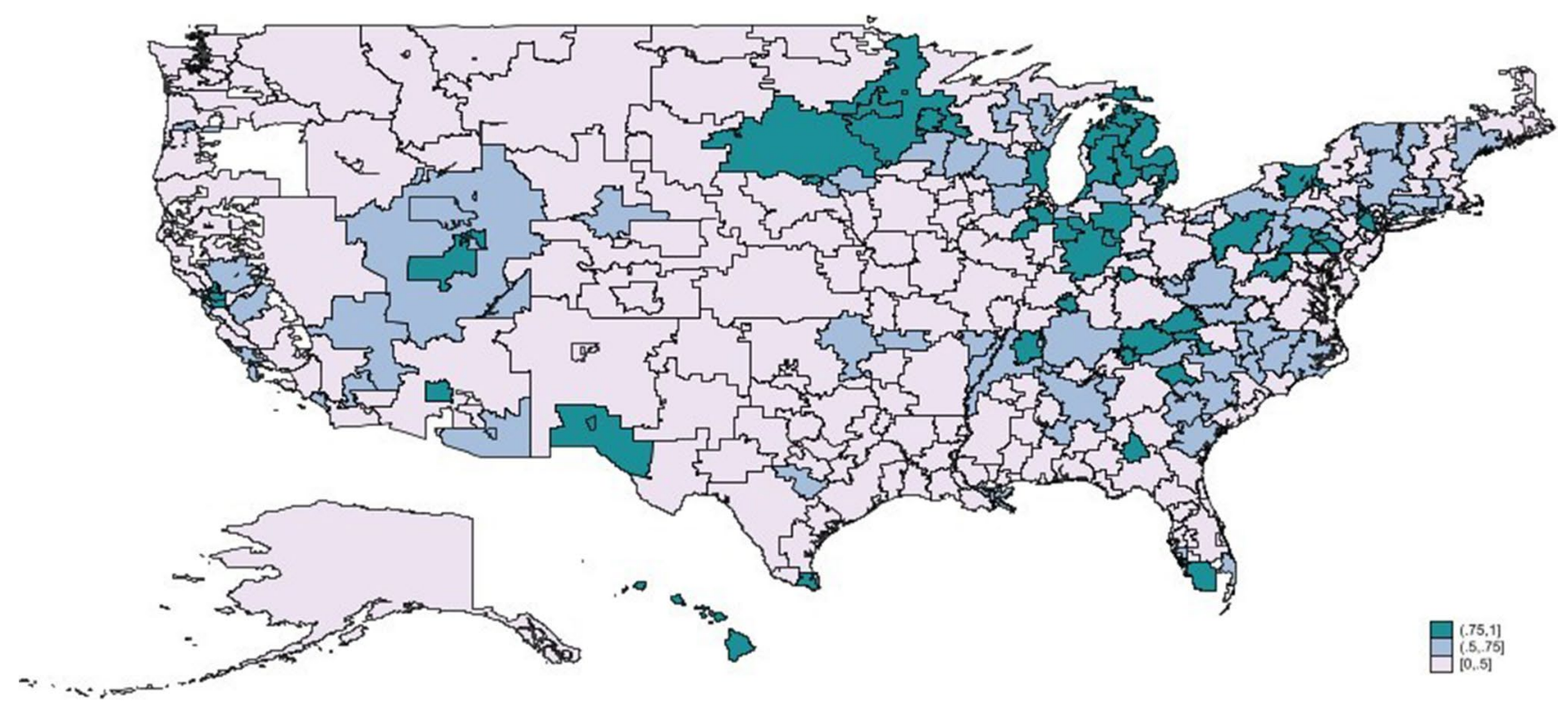

Figure 1 Compliance \% across hospital referral regions, June 1, 2021. Compliance \% is equivalent to the average compliance rating (0 or 1) in the HRR. A hospital is deemed noncompliant (compliance rating $=0$ ) if it had not posted any machine-readable pricing file or the file posted contained no commercial negotiated price information as of June 1, 2021. A hospital is deemed compliant (compliance rating =1) if it had posted a machine-readable file with commercial negotiated prices for at least one insurance plan as of June 1, 2021. No hospital information was available in the sample for one HRR (Bend, OR, colored white on the map). 
Table 1 List of HRRs with $0 \%$ and $100 \%$ Compliance

\begin{tabular}{ll}
\hline 0\%-compliant HRRs (26) & 100\%-compliant HRRs (20) \\
\hline AR-Fort Smith & AZ-Sun City \\
AR-Texarkana & CT-Bridgeport \\
CA-Salinas & GA-Albany \\
CA-Ventura & IL-Bloomington \\
DE-Wilmington & IN-Lafayette \\
FL-Clearwater & IN-Muncie \\
FL-Lakeland & KY-Covington \\
FL-Ormond Beach & KY-Owensboro \\
FL-St. Petersburg & MI-Dearborn \\
FL-Tampa & MI-Flint \\
IA-Cedar Rapids & MI-Petoskey \\
IA-Waterloo & MI-St. Joseph \\
IL-Hinsdale & NC-Hickory \\
LA-Alexandria & NJ-Paterson \\
MD-Salisbury & PA-Harrisburg \\
MD-Takoma Park & PA-Lancaster \\
MS-Meridian & PA-York \\
NJ-Ridgewood & TN-Johnson City \\
OH-Elyria & TN-Kingsport \\
SC-Florence & VA-Winchester \\
TX-Corpus Christi & \\
VA-Lynchburg & \\
VA-Newport News & \\
VA-Norfolk & \\
VA-Richmond & \\
WA-Yakima & \\
\hline
\end{tabular}

Compliance $\%$ is equivalent to the average compliance rating ( 0 or 1 ) in the HRR. $T$ tests for comparison of the means between HRRs with $0 \%$ compliance vs HRRs with $100 \%$ compliance: \# of hospitals $(5.01$ vs $4.05 ; P=0.22)$; HHI $(0.54$ vs $0.69 ; P=0.04)$; $\%$ for-profit hospitals $(0.12$ vs $0.04 ; P=0.15) ; \%$ government hospitals $(0.12$ vs 0.10 ; $P=0.79) ; \%$ system-affiliated hospitals $(0.74$ vs $0.79 ; P=0.62) ; \%$ non-urban hospitals $(0.71$ vs $0.56 ; P=0.16) ; \%$ teaching hospitals (0.30 vs $0.40 ; P=0.31)$; \# of discharges (4722 vs $3866 ; P=0.52)$; IT preparedness ( 0.03 vs $0.02 ; P=0.91$ ); profit margin ( 0.05 vs 0.04 ; $P=0.68)$; charge markup (4.95 vs $4.30 ; P=0.26)$; $\%$ Medicare discharge $(0.38$ vs $0.36 ; P=0.54)$, and $\%$ Medicaid $(0.07$ vs $0.05 ; P=$ $0.20)$

associated with compliance. These results remained robust when probit models were applied (Appendix Table 7).

HRR-level summary statistics are presented in Appendix Table 8, and the regression results are shown in Table 5. With or without controlling for the state fixed effects, HRRs with greater hospital concentrations (higher HHI) had more hospitals complying with the Price Transparency Rule $(P<0.03)$.

\section{DISCUSSION}

We conducted a nationwide analysis of US hospitals' compliance to the Hospital Price Transparency Final Rule that took effect on January 1, 2021. As of June 1, 2021, more than half (55\%) of short-term acute-care hospitals we examined either did not post any machine-readable file or their posted files contained no commercial negotiated price information. Wide variations of price transparency existed across states and HRRs. An individual hospital's compliance status was strongly associated with the average compliance level of peer hospitals in the same market, which suggests that hospitals may take into consideration the behavior of their peers in the same market when making price disclosure decisions.

It is worth emphasizing that, as supported by ample empirical evidence, organizational changes in health care do not take place rapidly even when the changes have the potential to bring organizational benefit. For example, revenue-generating practices diffused slowly in hospitals, potentially due to institutional frictions, ${ }^{20}$ and many accountable care organizations had significant delays in adopting performanceenhancing best practices and motivators designed to influence physician behaviors. ${ }^{21,22}$ Therefore, the learning and adoption process for all hospitals to achieve full compliance to the Hospital Price Transparency Rule probably requires a realistic timeline, especially considering the impact of the coronavirus pandemic on hospitals-significant resources are being diverted to managing new pandemic-related care delivery flows, accommodating the surge in demand due to deferred care, and implementing other imperative organizational changes to adapt to the fluid environment during the pandemic.

We found a robust positive association between a hospital's IT preparedness and its compliance to the Rule. The impact of hospital IT preparedness on organizational outcomes is an underexplored research area, primarily due to the lack of objective and comparable measurements of IT preparedness. Exploiting the unique mandatory reporting requirement in the Medicare cost report, our study contributed to this literature by suggesting that hospitals with better IT preparedness (with a higher investment in health IT in relation to total fixed assets) are more likely to comply to the Hospital Price Transparency Rule. To store pricing information with various payers for numerous hospital services requires nontrivial effort. For hospitals that have already made sufficient investment in health IT, the incremental resources needed and, by extension, the compliance cost for the Rule might be less intimidating. In contrast, hospitals with limited investment in health IT might face greater resource and knowledge obstacles in their compliance process, especially amid mounting challenges during the coronavirus pandemic.

In addition to IT preparedness, we found robust evidence that, holding other things equal, for-profit hospitals, system-affiliated hospitals, large hospitals, and hospitals located in non-urban areas on average had better compliance ratings. Compared to other hospitals, these hospitals might have more financial resources and personnel expertise to mitigate the cost required for the implementation of the Price Transparency Rule. They might also possess relatively stronger bargaining power so that even if negotiated commercial prices are disclosed, patients and 
Table 2 State Ranking, by Compliance \%

\begin{tabular}{|c|c|c|c|c|c|}
\hline Rank & State & \% compliance & Rank & State & $\%$ compliance \\
\hline 1 & $\mathrm{DC}$ & $100 \%$ & 27 & Illinois & $42 \%$ \\
\hline 2 & Hawaii & $88 \%$ & 28 & Ohio & $40 \%$ \\
\hline 3 & Rhode Island & $86 \%$ & 29 & Georgia & $40 \%$ \\
\hline 4 & Indiana & $80 \%$ & 30 & Wyoming & $40 \%$ \\
\hline 5 & Michigan & $75 \%$ & 31 & New York & $40 \%$ \\
\hline 6 & Minnesota & $74 \%$ & 32 & Mississippi & $39 \%$ \\
\hline 7 & Vermont & $73 \%$ & 33 & Oregon & $39 \%$ \\
\hline 8 & South Dakota & $71 \%$ & 34 & New Jersey & $38 \%$ \\
\hline 9 & Tennessee & $70 \%$ & 35 & Virginia & $36 \%$ \\
\hline 10 & Connecticut & $68 \%$ & 36 & New Mexico & $35 \%$ \\
\hline 11 & Pennsylvania & $66 \%$ & 37 & Kansas & $35 \%$ \\
\hline 12 & North Carolina & $62 \%$ & 38 & Nebraska & $34 \%$ \\
\hline 13 & West Virginia & $62 \%$ & 39 & Missouri & $34 \%$ \\
\hline 14 & Wisconsin & $59 \%$ & 40 & Texas & $34 \%$ \\
\hline 15 & Utah & $58 \%$ & 41 & Oklahoma & $32 \%$ \\
\hline 16 & Nevada & $54 \%$ & 42 & Montana & $32 \%$ \\
\hline 17 & South Carolina & $51 \%$ & 43 & Florida & $31 \%$ \\
\hline 18 & Alabama & $50 \%$ & 44 & North Dakota & $31 \%$ \\
\hline 19 & Arkansas & $47 \%$ & 45 & Maine & $28 \%$ \\
\hline 20 & Arizona & $46 \%$ & 46 & Alaska & $27 \%$ \\
\hline 21 & Kentucky & $44 \%$ & 47 & Colorado & $25 \%$ \\
\hline 22 & Iowa & $44 \%$ & 48 & Louisiana & $23 \%$ \\
\hline 23 & California & $44 \%$ & 49 & Washington & $21 \%$ \\
\hline 24 & Idaho & $43 \%$ & 50 & Maryland & $10 \%$ \\
\hline 25 & Massachusetts & $42 \%$ & 51 & Delaware & $0 \%$ \\
\hline 26 & New Hampshire & $42 \%$ & & & \\
\hline
\end{tabular}

Compliance $\%$ is equivalent to the average compliance rating ( 0 or 1$)$ in the state

$D C$ The District of Columbia

Table 3 Variable Definition and Summary

\begin{tabular}{|c|c|c|c|c|c|c|c|}
\hline Variable & Definition & $N$ & Mean & Std. Dv. & $25^{\text {th }}$ pet & Median & $75^{\text {th }}$ pet \\
\hline Compliance rating & 1 if compliant, 0 if otherwise & 3558 & 0.45 & 0.50 & 0 & 0 & 1 \\
\hline For profit & 1 if a for-profit hospital, 0 if otherwise & 3558 & 0.19 & 0.39 & 0 & 0 & 0 \\
\hline Government & 1 if a government hospital, 0 if otherwise & 3558 & 0.19 & 0.40 & 0 & 0 & 0 \\
\hline System & 1 if system-affiliated, 0 if otherwise & 3558 & 0.65 & 0.48 & 0 & 1 & 1 \\
\hline Non-urban & 1 if non-urban, 0 if otherwise & 3558 & 0.47 & 0.50 & 0 & 0 & 1 \\
\hline Teaching & 1 if teaching hospital, 0 if otherwise & 3558 & 0.30 & 0.46 & 0 & 0 & 1 \\
\hline Log (discharges) & Logarithm of \# of discharges & 3558 & 7.77 & 1.85 & 6.43 & 8.12 & 9.28 \\
\hline Market share & System-adjusted market share on the HRR & 3558 & 0.19 & 0.23 & 0.02 & 0.09 & 0.28 \\
\hline IT preparedness & Health IT assets/total fixed assets & 3558 & 0.05 & 0.13 & 0 & 0 & 0.02 \\
\hline Profit margin & Overall net income/net patient revenue & 3558 & 0.05 & 0.14 & -0.01 & 0.05 & 0.12 \\
\hline Charge markup & Charge/Medicare-allowable cost & 3558 & 4.17 & 2.63 & 2.30 & 3.64 & 5.25 \\
\hline Medicare \% & Medicare discharge/total discharge & 3558 & 0.38 & 0.16 & 0.26 & 0.35 & 0.46 \\
\hline Medicaid \% & Medicaid discharge/total discharge & 3558 & 0.08 & 0.09 & 0.02 & 0.04 & 0.11 \\
\hline Peer compliance* & $\begin{array}{l}\text { Average compliance rating of other hospitals } \\
\text { in the HRR }\end{array}$ & 3557 & 0.45 & 0.25 & 0.27 & 0.44 & 0.60 \\
\hline
\end{tabular}

*One observation was lost for "Peer compliance" because one HRR (St. Joseph, MI) has only one hospital in the sample, and thus, no peer compliance was available 
Table 4 Factors Associated with Hospital Compliance Rating

\begin{tabular}{|c|c|c|c|c|}
\hline Variable & (1) & (2) & (3) & (4) \\
\hline For profit & $\begin{array}{l}0.084 * * * \\
(0.001)\end{array}$ & $\begin{array}{l}0.089 * * * \\
(0.001)\end{array}$ & $\begin{array}{l}0.079 * * * \\
(0.004)\end{array}$ & $\begin{array}{l}0.083 * * * \\
(0.001)\end{array}$ \\
\hline Government & $\begin{array}{l}-0.013 \\
(0.574)\end{array}$ & $\begin{array}{l}0.030 \\
(0.227)\end{array}$ & $\begin{array}{l}0.016 \\
(0.561)\end{array}$ & $\begin{array}{l}0.025 \\
(0.323)\end{array}$ \\
\hline System & $\begin{array}{l}0.148 * * * \\
(0.000)\end{array}$ & $\begin{array}{l}0.137 * * * \\
(0.000)\end{array}$ & $\begin{array}{l}0.151 * * * \\
(0.000)\end{array}$ & $\begin{array}{l}0.142 * * * \\
(0.000)\end{array}$ \\
\hline Non-urban & $\begin{array}{l}0.091 * * * \\
(0.000)\end{array}$ & $\begin{array}{l}0.054 * * * \\
(0.006)\end{array}$ & $\begin{array}{l}0.070 * * * \\
(0.001)\end{array}$ & $\begin{array}{l}0.059 * * * \\
(0.002)\end{array}$ \\
\hline Teaching & $\begin{array}{l}0.044 * * \\
(0.045)\end{array}$ & $\begin{array}{l}0.032 \\
(0.135)\end{array}$ & $\begin{array}{l}0.011 \\
(0.630)\end{array}$ & $\begin{array}{l}0.024 \\
(0.256)\end{array}$ \\
\hline $\begin{array}{l}\text { Log (\# of dis- } \\
\text { charges) }\end{array}$ & $\begin{array}{l}0.013^{*} \\
(0.064)\end{array}$ & $\begin{array}{l}0.021 * * * \\
(0.003)\end{array}$ & $\begin{array}{l}0.022 * * * \\
(0.003)\end{array}$ & $\begin{array}{l}0.023 * * * \\
(0.001)\end{array}$ \\
\hline Market share & $\begin{array}{l}0.169 * * * \\
(0.000)\end{array}$ & $\begin{array}{l}0.106 * * * \\
(0.009)\end{array}$ & $\begin{array}{l}0.088^{*} \\
(0.087)\end{array}$ & $\begin{array}{l}0.078 * * \\
(0.042)\end{array}$ \\
\hline IT preparedness & $\begin{array}{l}0.129 * * \\
(0.045)\end{array}$ & $\begin{array}{l}0.164 * * \\
(0.013)\end{array}$ & $\begin{array}{l}0.145 * * \\
(0.035)\end{array}$ & $\begin{array}{l}0.160 * * \\
(0.016)\end{array}$ \\
\hline Profit margin & $\begin{array}{l}-0.042 \\
(0.463)\end{array}$ & $\begin{array}{l}-0.027 \\
(0.637)\end{array}$ & $\begin{array}{l}-0.040 \\
(0.494)\end{array}$ & $\begin{array}{l}-0.029 \\
(0.614)\end{array}$ \\
\hline Charge markup & $\begin{array}{l}-0.008^{*} \\
(0.091)\end{array}$ & $\begin{array}{l}0.002 \\
(0.728)\end{array}$ & $\begin{array}{l}0.004 \\
(0.483)\end{array}$ & $\begin{array}{l}0.001 \\
(0.786)\end{array}$ \\
\hline Medicare $\%$ & $\begin{array}{l}-0.139 * * \\
(0.026)\end{array}$ & $\begin{array}{l}-0.073 \\
(0.281)\end{array}$ & $\begin{array}{l}-0.122^{*} \\
(0.088)\end{array}$ & $\begin{array}{l}-0.074 \\
(0.272)\end{array}$ \\
\hline Medicaid \% & $\begin{array}{l}-0.251^{* * * *} \\
(0.005)\end{array}$ & $\begin{array}{l}-0.277 * * * \\
(0.005)\end{array}$ & $\begin{array}{l}-0.148 \\
(0.146)\end{array}$ & $\begin{array}{l}-0.223^{* *} \\
(0.024)\end{array}$ \\
\hline Peer compliance & & & & $\begin{array}{l}0.422 * * * \\
(0.000)\end{array}$ \\
\hline State fixed effects & No & Yes & No & Yes \\
\hline HRR fixed effects & No & No & Yes & Yes \\
\hline$N$ & 3558 & 3558 & 3558 & $3557^{\dagger}$ \\
\hline Adj. $R$ squared & 0.048 & 0.126 & 0.195 & 0.155 \\
\hline
\end{tabular}

The dependent variable is compliance rating $(0$ or 1$)$. Linear probability models are used. $P$ values are based on robust standard errors and are in parentheses. Coefficients are reported, except for constants. The results remained qualitatively unchanged if the 891 hospitals excluded from the sample (because their machine-readable files cannot be automatically processed) were reclassified as noncompliant and included in the sample

${ }^{\dagger}$ One observation was lost in model (4) because one HRR (St. Joseph, MI) has only one hospital in the sample, and thus, no peer compliance was available

*** $P<0.001 ; * * P<0.05 ; * P<0.1$

payers - constrained by their limited options — would not be able to obtain a lower price. It is worth noting that hospitals in Maryland had the second lowest compliance rate (10\%) among all 50 states and the District of Columbia. Maryland's all-payer model, which requires that hospitals receive the same payment across all types of payers for the same hospital services, reduces hospitals' incentive to make a strategic compliance decision to obtain a competitive advantage over other hospitals. ${ }^{23,24}$ The low compliance rate among Maryland hospitals, therefore, suggests that
Table 5 Factors Associated with HRR Average Compliance Rating

\begin{tabular}{|c|c|c|}
\hline Variable & (1) & (2) \\
\hline Log (\# of hospitals in the HRR) & $\begin{array}{l}0.040 \\
(0.198)\end{array}$ & $\begin{array}{l}0.041 \\
(0.159)\end{array}$ \\
\hline HHI & $\begin{array}{l}0.293 * * \\
(0.020)\end{array}$ & $\begin{array}{l}0.270 * * \\
(0.026)\end{array}$ \\
\hline Average for profit & $\begin{array}{l}0.100 \\
(0.347)\end{array}$ & $\begin{array}{l}0.131 \\
(0.219)\end{array}$ \\
\hline Average government & $\begin{array}{l}-0.026 \\
(0.736)\end{array}$ & $\begin{array}{l}0.124 \\
(0.197)\end{array}$ \\
\hline Average system & $\begin{array}{l}0.084 \\
(0.343)\end{array}$ & $\begin{array}{l}-0.018 \\
(0.849)\end{array}$ \\
\hline Average non-urban & $\begin{array}{l}0.099 \\
(0.237)\end{array}$ & $\begin{array}{l}-0.037 \\
(0.643)\end{array}$ \\
\hline Average teaching & $\begin{array}{l}0.159 * \\
(0.097)\end{array}$ & $\begin{array}{l}0.154 \\
(0.123)\end{array}$ \\
\hline Log (average \# of discharges) & $\begin{array}{l}0.006 \\
(0.864)\end{array}$ & $\begin{array}{l}0.008 \\
(0.848)\end{array}$ \\
\hline Average IT preparedness & $\begin{array}{l}-0.113 \\
(0.718)\end{array}$ & $\begin{array}{l}-0.228 \\
(0.492)\end{array}$ \\
\hline Average profit margin & $\begin{array}{l}-0.329 \\
(0.279)\end{array}$ & $\begin{array}{l}0.125 \\
(0.690)\end{array}$ \\
\hline Average charge markup & $\begin{array}{l}-0.014 \\
(0.347)\end{array}$ & $\begin{array}{l}0.007 \\
(0.739)\end{array}$ \\
\hline Average Medicare $\%$ & $\begin{array}{l}-0.422^{*} \\
(0.060)\end{array}$ & $\begin{array}{l}-0.126 \\
(0.598)\end{array}$ \\
\hline Average Medicaid $\%$ & $\begin{array}{l}-0.257 \\
(0.399)\end{array}$ & $\begin{array}{l}-0.977 * \\
(0.061)\end{array}$ \\
\hline State fixed effects & No & Yes \\
\hline$N$ & $305^{\dagger}$ & 305 \\
\hline Adj. $R$ squared & 0.052 & 0.249 \\
\hline
\end{tabular}

The dependent variable is the average hospital compliance rating in the HRR. $P$ values are based on robust standard errors and are in parentheses. Coefficients are reported, except for constants

HHI Herfindahl-Hirschman Index

$* * P<0.05 ; * P<0.1$

${ }^{\dagger}$ No hospital information was available in one HRR (Bend, OR)

logistical and financial burdens faced by hospitals, rather than a lack of desire to disclose pricing in order to gain a competitive advantage, might be a dominant factor in influencing hospital compliance to the Rule.

HRR-level analyses suggested that more concentrated hospital markets had greater average compliance. This was not particularly surprising because concentrated markets were more likely to contain hospitals with more resources and one hospital's compliance decision could have a spillover effect on its peers in the same market (as suggested by this study). However, due to the unavailability of data on the disclosure sequence among hospitals within the same market, we were unable to empirically test how hospitals actually interacted in their compliance decisions, which can be a promising future research area. 
This study has several limitations. First, although hospital compliance and pricing data generated by Turquoise Health has been used in several recent studies, ${ }^{11-13}$ the data is subject to potential inaccuracies caused by errors in its automated collecting and compiling process. Next, the starting date for each hospital's price disclosure is unavailable, which prevented us from examining the sequence of disclosure activities across hospitals. In addition, we constructed a binary measurement of hospital compliance to limit the subjectivity in categorizing hospitals. This measure, however, is unable to recognize the varying degree of compliance-such as the number of services being disclosed - across hospitals that posted a machine-readable file containing the commercial negotiated price for at least one insurance plan. Similarly, hospitals that comply with the machine-readable requirement but not the consumer-friendly display mandate cannot be identified. Moreover, although sensitivity analysis confirmed the robustness of our results, the compliance status of the 891 hospitals excluded from the sample due to data-processing challenges remains unclear. Furthermore, this study, limited by its descriptive nature, cannot provide evidence to suggest any causal relationship.

\section{CONCLUSION}

By mandating price disclosure, the federal government aims to offer patients, employers, other third-party payers, and the general public the price information needed for informed decision-making and, by extension, enhance market competition and improve the affordability of hospital care. ${ }^{1}$ However, a low compliance level among hospitals would compromise the operational effectiveness of this regulation. The main findings of this study suggest that the compliance cost might be a barrier for some hospitals.

Corresponding Author: Ge Bai PhD, CPA; Johns Hopkins Carey Business School, Baltimore, MD, USA (e-mail: gbai@ jhu.edu).

Supplementary Information The online version contains supplementary material available at https://doi.org/10.1007/s11606-021-07237-y.

\section{Declarations}

Jeff Littlejohn is a solutions engineer at Turquoise Health, a data service company focused on health care price transparency. We thank Gerard Anderson for his valuable comments. This research is supported by Arnold Ventures.

Conflict of Interest The authors declare that they do not have a conflict of interest.

\section{References}

1. Centers for Medicare and Medicaid Services. CMS completes historic price transparency initiative. CMS. Posted October 29 2020. Accessed July 1, 2021. https://www.cms.gov/newsroom/ press-releases/cms-completes-historic-price-transparency-initiative
2. National Archives and Records Administration. Hospital Price Transparency. NARA. Posted November 27, 2019. Accessed July 1, 2021. https://ecfr.federalregister.gov/current/title-45/subti tle-A/subchapter-E/part-180

3. Centers for Medicare and Medicaid Services. CY2022 Medicare hospital outpatient prospective payment system and ambulatory surgical center payment system proposed rule (CMS-1753-P). CMS. Posted July 19, 2021. Accessed September 25, 2021. https://www.cms. gov/newsroom/fact-sheets/cy-2022-medicare-hospital-outpatientprospective-payment-system-and-ambulatory-surgical-center

4. Centers for Medicare and Medicaid Services. Medicare program: Proposed changes to hospital outpatient prospective payment and ambulatory surgical center payment systems and quality reporting programs; price transparency of hospital standard charges; etc. CMS. Posted August 9, 2019. Accessed July 1, 2021. https://www.regulations. gov/document/CMS-2019-0109-0002/comment

5. United States Courts. American Hospital Association v. Alex Azar, II. US Courts. Posted December 29, 2020. Accessed July 1, 2021. https:// www.cadc.uscourts.gov/internet/opinions.nsf/CCDF215AFCAF25 F98525864D005716BC/\$file/20-5193-1877500.pdf

6. American Hospital Association. AHA letter to Biden-Harris transition team on price transparency rule. AHA. Posted December 21, 2020. Accessed July 1, 2021. https://www.aha.org/ lettercomment/2020-12-21-aha-letter-biden-harris-transition-team-price-transparency-rule

7. Henderson M, Mouslim MC. Low compliance from big hospitals on CMS's Hospital Price Transparency Rule. Health Aff Blog 202 1. https: //doi.org/10.1377/hblog20210311.899634

8. Xiao R, Rathi VK, Gross CP, Ross JS, Sethi RK. Payer-negotiated prices in the diagnosis and management of thyroid cancer in 2021. JAMA 2021. https://doi.org/10.1001/jama.2021.8535

9. Gondi S, Beckman AL, Ofoje AA, Hinkes P, McWilliams JM. Early hospital compliance with federal requirements for price transparency. JAMA Intern Med 2021. https://doi.org/10.1001/jamaintern med.2021.2531

10. https://turquoise.health. Turquoise's price transparency data has been used by the Wall Street Journal and National Public Radio. A random check of some large hospitals didn't reveal any inaccuracy of the data

11. Mulaney B, Shah SA, Kim C, Baker LC. Compliance with price transparency by California hospitals. Posted July 10, 2021. Accessed September 25, 2021. https://healthpolicy.fsi.stanford.edu/publication/ compliance-price-transparency-california-hospitals

12. Jiang J, Makary M, Bai G. Where are the high-price hospitals? With the Transparency Rule in effect, colonoscopy prices suggest that they're all over the place. Health Aff Blog 2021. https://doi.org/10.1377/hblog20210805.748571

13. Jiang J, Makary M, Bai G. Commercial negotiated prices for CMSspecified shoppable surgery services in U.S. hospitals. Int J Surg. 2021. https://doi.org/10.1016/j.jjsu.2021.106107

14. Centers for Medicare and Medicaid Services. Hospital 2552-2010 form. CMS. 2021. Accessed July 1, 2021. 2019 Hospital Cost Reports were used. https://www.cms.gov/Research-StatisticsData-and-Systems /Downloadable-Public-Use-Files/Cost-Repor ts/Hospital-2010-form.html

15. The 891 excluded hospitals are smaller than the hospitals in the sample (median \# beds: 25 vs. $88, P<0.01$; IQR: $24-115$ vs. 25-216). On September 20, 2021, we randomly selected 30 hospitals and confirmed data-processing challenges for 28 of them. The remaining two hospitals posted machine-readable pricing files. However, we cannot identify whether the files were posted prior to June 1, 2021.

16. Bai G, Anderson GF. A more detailed understanding of factors associated with hospital profitability. Health Aff (Millwood) 2016;35(5):889-97. https://doi.org/10.1377/hlthaff.2015.1193

17. Dartmouth Atlas. Supplemental research data. Dartmouth Atlas. 2021. . https://atlasdata.dartmouth.edu/downloads/supplement al

18. Bai G, Anderson GF. Extreme markup: The fifty US hospitals with the highest charge-to-cost ratios. Health Aff (Millwood) 2015;34(6):922-8. https://doi.org/10.1377/hlthaff. 2014. 1414

19. Lindrooth RC, Konetzka RT, Navathe AS, Zhu J, Chen W, Volpp $\mathrm{K}$. The impact of profitability of hospital admissions on mortality. 
Health Serv Res. 2013;48(2):792-809. https://doi.org/10.1111/ 1475-6773.12026

20. Sacarny A. Adoption and learning across hospitals: The case of a revenue-generating practice. National Bureau of Economic Research. 2018. . https://www.nber.org/papers/w24497

21. D'Aunno T, Broffman L, Sparer M, Kumar SR. Factors that distinguish high-performing accountable organizations in the Medicare Shared Savings Program. Health Serv Res 2018;53(1):120-137. https://doi.org/10.1111/1475-6773.642

22. Phipps-Taylor M, Shortell SM. More than money: Motivating physician behavior change in accountable care organizations. Milbank $\mathrm{Q}$ 2016; 94(4):832-861. https://doi.org/10.1111/1468-0009.12230
23. Roberts ET, Hatfield LA, McWilliams JM, Chernew ME, Done N, Gerovich S, Gilstrap L, Mehrotra A. Change in hospital utilization three years into Maryland's global budget program for rural hospitals. Health Aff (Millwood) 2018;37(4):644-653. https://doi. org/10.1377/hlthaff.2018.0112

24. Centers for Medicare and Medicaid Services. Maryland all-payer model. CMS. Updated May 4, 2021. Accessed September 25, 2021. https://innovation.cms.gov/innovation-models/maryl and-all-payer-model

Publisher's Note Springer Nature remains neutral with regard to jurisdictional claims in published maps and institutional affiliations. 